\title{
Does Thinking Style Affect the Impacts of Satisfaction and Reputation on Repurchase Intention? A Cross-National Comparison
}

\author{
Assoc. Prof. Dr. Oznur Ozkan Tektas ${ }^{1}$ \\ oznuro@hacettepe.edu.tr \\ Assoc. Prof. Dr. Canan Eryigit \\ canand@hacettepe.edu.tr \\ Assist. Prof. Dr. Ozge Tayfur Ekmekci \\ otayfur@hacettepe.edu.tr \\ Hacettepe University \\ Department of Business Administration \\ Ankara TURKEY \\ +90312 2978700
}

Received: 20 March 2017/ Revised: 10 May 2017/ Accepted: 15 May 2017/Published online: 4 August 2017

\begin{abstract}
The purpose of this study is to test whether the influence of satisfaction and reputation on repurchase intention varies among analytic and holistic thinkers. We employed an individual level approach to measure cross-cultural differences regarding thinking style and other variables. We made a cross-cultural comparison via analyzing the effects of satisfaction and firm reputation on repurchase intention, using data from the USA and Turkey that reflect analytic and holistic thinking cultures, respectively. Also, we conducted intra-cultural analyses in which the USA data and Turkish data were analyzed separately. Findings from these analyses revealed that holistic and analytic thinking styles create differences at the individual level (intra-cultural) but not at the cultural level (cross-cultural). In the Turkish sample, the impact of reputation on repurchase intention is found to be stronger than that of satisfaction for holistic thinkers.
\end{abstract}

JEL classification: M3, M31

Keywords: holistic thinking, analytic thinking, customer satisfaction, firm reputation, repurchase intention

\section{INTRODUCTION}

Repurchase intention of a consumer is considered as a strong predictor of purchasing behavior since a person's intention to behave in a certain way is the immediate determinant of that action (Ajzen, 2011). Consequently, firms working to sustain their operations and profitability must determine the factors that trigger repurchase intention among consumers. Satisfaction and

1 Corresponding author 
reputation have been widely accepted as the two strongest factors affecting repurchase intention. However, certain consumer characteristics may result in differences in their relative influence (e.g., Dong et al., 2011). For example, analytic and holistic thinking styles may influence the predictive power of satisfaction and reputation on repurchase intention. While the analytic thinking style involves detachment of the object from its context, holistic thinking involves an orientation to the context as a whole (Nisbett et al., 2001). Holistic and analytic thinking styles can impact how consumers evaluate products purchased and their responses to a brand's actions (Liang, 2008; Monga and John, 2008). Consumers using an analytic thinking style may rely on satisfaction to guide their purchasing behavior since satisfaction is a more internal and cognitive, product-based evaluation of what is expected versus what is received. On the other hand, consumers using a holistic thinking style may also consider satisfaction but depend more on reputation as an external source of information. In the consumer behavior literature, the effects of holistic and analytic thinking styles have been studied in connection with new product diffusion (Kottonau et al., 2000), brand extension evaluation (Monga and John, 2007; Yoon and GurhanCanli, 2004), advertising evaluation (Liang, 2008), and brand publicity (Monga and John, 2008). However, we encountered no studies to date on the role of holistic and analytic thinking styles on the relationship across consumer satisfaction, reputation, and repurchase intention.

Specifically, the USA (United States of America) and East Asian cultures have been studied in the consumer psychology literature in terms of the effect of holistic and analytic thinking styles on consumer behavior. Turkey - representing an Eastern, non-Asian culture-however, has not been studied in terms of differing thinking styles in consumer behavior. With its strategic location and growing population, Turkey has been identified as one of the major emerging markets for global business (Jennings, 1996). At the same time, most of the current knowledge concerning psychology and other related disciplines (i.e., consumer behavior) has emerged from the Western world, especially North America. Yet theories developed in one sociocultural context cannot always be applied effectively in other contexts (Wasti, 1998). Even so, the need to use and apply existing theories in other sociocultural contexts and compare their results with those obtained in Western cultures has emerged as a viable research tool, primarily as a means to generalize contemporary research and knowledge, despite the inherent limitations.

Based on this premise, the purpose of this study is to test whether the influence of satisfaction and reputation on repurchase intention varies among analytic and holistic thinkers. We employed an "individual level approach" to measure cross-cultural differences regarding thinking style and other variables. In this approach, hypotheses were examined both intra-culturally and cross-culturally, enabling us to test explanatory variables at two levels (Berry and Dasen, 1974). That is because a cross-cultural comparison may be contaminated because members from different cultures may have a different number of baseline thoughts across situations (Liang, 2008).

Accordingly, the hypotheses were tested in different designs. At first, we analyzed the effects of satisfaction and firm reputation on repurchase intention, using data from the US sample and the Turkish sample, with the aim of determining whether the impact of satisfaction and reputation on repurchase intention differed substantially in two different societies, thereby cultures. Employing the individual-level approach, participants' responses from each sample were aggregated separately, with each variable's aggregated scores used to make cross-cultural comparisons in determining whether the hypothesized relations differed in magnitude and size in the two sample sets. Using data from the US sample and the Turkish sample, respectively, the second design tested whether the effects of satisfaction and reputation on repurchase intention differed for people, depending on their use of either holistic or analytic thinking styles. These studies utilized intra-cultural analyses, which means separately analyzing the US data and Turkish data. Doing so allows for accounting for within-country differences, with respect to the thinking style.

This study contributes to the consumer behavior literature by expanding the knowledge of the discipline concerning repurchase intention's antecedents in considering the effects of holistic 
and analytic thinking styles. Although many studies (e.g. Walsh and Beatty, 2011; Bloemer and Kasper, 1995; Dong et al., 2011; Mittal and Kamakura, 2001; Suh and Yi, 2006) examined the factors (e.g. demographics, experience, variety seeking, culture) influencing the effect of satisfaction and reputation on repurchase intentions, no studies on the role of thinking style have been encountered. However, people base their attitude and evaluation on attribute-relevant and cognitive information processing or attribute-irrelevant information and peripheral cues. In social psychology and consumer behavior literature, models such as Elaboration Likelihood Model (Petty and Cacioppo, 1979) and the Heuristic Systematic Model (Chaiken, 1980:212) explain the reasoning of people's attributions and information processing based on involvement level and message characteristic. Subsequently, a consumer's thinking style may influence whether he/she considers satisfaction or reputation as more important in making a repurchase decision. Therefore, understanding how the thinking style plays a role in evaluating two important antecedents of repurchase intention may contribute to the current knowledge.

Further, this study may also contribute to an examination of thinking styles at both cultural and individual levels. To our knowledge, no study has used thinking style as a basis for studying its impact at individual and cultural levels, simultaneously. We expect that testing the effect of thinking style within and between cultures will shed light on whether thinking style should be treated as an individual or a cultural difference variable while advising marketing policies.

\section{LITERATURE REVIEW}

\subsection{Repurchase Intention, Customer Satisfaction and Firm Reputation Relation}

Repurchase intention is defined as "the individual's judgment about buying again a designated service from the same company considering his or her current situation and circumstances" (Hellier et al., 2003, p. 1764). Barring unforeseen and uncontrollable events, people are expected to act in accordance with their intentions (Ajzen, 2011).

Accordingly, repurchase intention is considered an important indicator of making an actual purchase (Ajzen, 2011; Chang and Wildt, 1994). Therefore, the primary concern in consumer behavior literature is to identify the factors that shape and determine repurchase intention, which have been operationalized as a willingness to recommend to others, displaying intent to repurchase, or offering positive or negative word of mouth and feedback. In accord with its importance, a considerable number of studies have been conducted to determine repurchase intention's antecedents (e.g., Agustin and Singh, 2005; Brady et al., 2005; Caruana and Ewing, 2009; Chang and Wildt, 1994; Hellier et al., 2003). In many of them, customer satisfaction and firm reputation have been listed among the most important antecedents of repurchase intention.

Broadly, customer satisfaction reflects an evaluation of perceived consistency between prior beliefs, expectations, and a product's actual performance (Grigoroudis and Siskos, 2010; Oliver, 1999). Satisfaction is therefore "the overall level of customer pleasure and contentment resulting from experience with the service" (Hellier et al., 2003, p.1764). Understanding customer satisfaction is critical, given the substantial number of studies reporting a positive relationship between customer satisfaction and repurchase intention for a wide variety of product and country settings (e.g., Agustin and Singh, 2005; Anderson and Sullivan, 1993; Bolton and Drew, 1991; Brady et al., 2005; Byoungho et al., 2008; Choi et al., 2004; Cronin et al., 2000; Hellier et al., 2003; Lai et al., 2009; Zins, 2001). Previous studies state that satisfaction is an affective outcome of a cognitive evaluation process that compares actual product performance with some internal standards (Dube and Schmitt, 1991). According to expectancy disconfirmation model, satisfaction judgments have cognitive internal comparison and cognitive post purchase outcomes that turn into behavior (Oliver, 1980). 
Another important determinant of repurchase intention is firm reputation. Reputation has been defined as "how well the firm meets its commitments and conforms to stakeholders' expectations" (Cretu and Brodie, 2007, p. 232). Past research (e.g., Byoungho et al., 2008; Caruana and Ewing, 2009; Nguyen and LeBlanc, 2001; Nikbin et al., 2011; Selnes, 1993; Yoon et al., 1993) has supported reputation's positive influence on repurchase intention for various product categories, such as life insurance, education, airlines, online purchasing, and mobile phones.

Although studies have demonstrated that satisfaction and reputation are important antecedents of repurchase intention, such effects may vary, based on consumer characteristics (Dong et al., 2011). Therefore, the impact of satisfaction and reputation on repurchase intention is subject to the influence of moderator variables. Several studies (Aydin et al., 2005; Bartikowski et al., 2011; Bloemer and De Ruyter, 1998; Bloemer and Kasper, 1995; Chen and Tsai, 2008; Dong et al., 2011; Homburg and Giering, 2001; Mittal and Kamakura, 2001; Suh and Yi, 2006; Walsh et al., 2008; Yang and Peterson, 2004) have examined the roles of customer demographics and psychographics in the relationship among satisfaction, reputation, and repurchase intention. Such factors as education level, sex, marital status, age, experience, critical incidents, variety seeking, switching costs, gender, income, culture, elaboration, and involvement have been analyzed as variables affecting the influence of reputation and satisfaction on repurchase intention. The role of thinking style in this relationship has been underestimated; whereas consumers' thinking style is one of the important factors that affect how they perceive, explain, and evaluate objects, events, brands, and products.

\subsection{Thinking Style: Holistic Versus Analytic}

Thinking style refers to an individual's preference for processing information in a particular way (Borroughs, 1996; Smith and Baron, 1981). The different ways of thinking are based primarily on different views of the self (Markus and Kitayama, 1991). If for example the self is seen as independent, people behave consistently across different situations independent from the environment. However, individual behaviors vary in different situations if the self is seen as interdependent with the environment (Liang, 2008). In general, a person has two modes of thinking style. The holistic thinking style involves "an orientation to the context or field as a whole, including attention to relationships between a focal object and the field, and a preference for explaining and predicting events on the basis of such relationships" (Nisbett et al., 2001, p. 293). In contrast, the analytic thinking style involves "detachment of the object from its context, a tendency to focus on attributes of the object to assign it to categories, and a preference for using rules about the categories to explain and predict the object's behavior" (Nisbett et al., 2001, p. 293).

Holistic thinking is characterized by giving broad attention to the context and relationships. People who employ a holistic thinking style grasp the overall idea; they see the "big picture." They may seem less attentive to details and do not separate an object into its parts to understand it; instead, they try to understand the general meaning, focusing on relationships between objects (Monga and John, 2004). Holistic thinkers tend to focus on background elements and believe that external forces or situations lead to events. A holistic style may require less cognitive effort thus providing the advantage of speed (Burroughs, 1996). Conversely, an analytic style requires more effort (Burroughs, 1996) and is characterized by logical reasoning. Analytic thinkers pay close attention to the internal attributes of a situation or object. Analytic thought engages symbolic representational systems (Nisbett et al., 2001) in which the focal object can be more easily isolated from its background, allowing for a focus on an object's attributes (Monga and John, 2004). Holistic thinkers use both internal object-based evaluations and external context-based explanations, with emphasis on the latter one, whereas analytic thinkers tend to rely on internal object-based evaluations (Monga and John, 2008). Analytic and holistic thinking can also be 
conceptualized by the tendency to see behavior as an outcome of one's dispositions and to ignore important situational determinants of the behavior, which is known as correspondent bias (Gilbert and Malone, 1995). Analytic thinkers have a tendency to make more dispositional attributions while holistic thinkers are more likely to make contextual attributions (Liang, 2008).

Thinking style has been measured and conceptualized as an individual and cultural differences variable. The holistic-versus-analytic distinction was first conceptualized in cognitive psychology literature as an individual reasoning tool (Burroughs, 1996; Hutchinson and Alba, 1991; Smith and Baron, 1981). In consumer behavior literature, a limited number of studies have treated holistic or analytic thinking styles as individual difference variables (e.g., Choi et al., 2007; Monga and John, 2008). Recently, with Nisbett et al.'s (2001) study, it has been conceptualized as a source of cultural differences in cultural psychology literature. The logic behind cultural conceptualization is that people with different cultural backgrounds may perform differently on various attribution tasks (Jen and Lien, 2010) such as different views of the self. Subsequently, a framework using the two styles was adopted in several studies to predict cross-cultural differences (i.e., Choi et al., 2003; Jen and Lien, 2010; Liang, 2008; Monga and John, 2004). Nisbett et al. (2001) have observed that differences in thinking styles across cultures are shaped by differences in social orientation (number and intensity of social relations). Cultures that have a more independent and autonomous view of the self, such as the US, are characterized by populations more likely to think analytically (Choi et al., 2003). Since in independent social systems, members socialize into an autonomous and independent environment, social relations are not intensive. This makes an individual focus on relevant objects without paying much attention to the way they interact with other people and tend to direct their attention to internal attribute evaluations. Thus, independent social relations encourage an analytic thinking style (Uskul et al., 2008). Other cultures emphasizing relatedness and interdependence with the social world, such as those in East Asia (e.g., Japan), are characterized with populations more likely to think holistically (Miyamoto et al., 2013). People in those cultures are more likely to attend to the perceptual field as a whole, perceive relationships between the main object and the field, and explain events on the basis of such relationships (Uskul et al., 2008). They focus on contextual factors rather than dispositional factors in understanding and predicting events or objects (Liang, 2008).

Although considerable research posits that people from the US use an analytic thinking style (e.g. Miyamoto et al., 2013), no similar research has been conducted about the Turkish people. However, other cultural difference frameworks state that Turkey is closer to a holistic thinking culture. For instance, according to Hofstede (2001), Turkey is a collectivist culture that gives credence to interdependence and relations with others. Further, according to Hall (1976), Turkey has a high-context culture in which interdependent relations among people and objects are important. In contrast to Turkey, Americans live in a low-context (Hall, 1976), more individualistic (Hofstede, 2001), and independent society. In addition to these cultural differences, Kanungo and Jaeger (1990) have provided an abstractive-thinking versus an associative-thinking conceptualization, as applied to comparing cultural differences between developed and developing countries. People living in abstractive cultures tend to be influenced more by abstract rules and principles applied equally to each situation. For those living in associative cultures, context plays an important role in determining an an individual's perceptions, attributes, and behaviors. Developed countries are more context-independent, reflecting an abstractive mode of thinking (similar to analytic thinking); whereas developing countries tend to be more context-dependent. This is related to the associative mode of thinking and similar to the holistic thinking style. In her study, Wasti (1998) classified Turkey as an associative thinking culture and the United States as an abstract thinking culture. Thus, in our study, Turkey and the United States have been chosen to represent holistic and analytic cultures, respectively. 


\subsection{The Role of Thinking Style in the Satisfaction-Reputation-Repurchase Intention Relation}

Consumers' thinking styles may affect their evaluation of products they purchase and their responses to a brand's behavior (Liang, 2008; Monga and John, 2008). To reiterate our premise stated in the preceding section, consumer behavior literature offers studies on the effect of analytic versus holistic thinking style differences, which have been investigated both from an individual standpoint (Choi et al., 2007) as well as from a cultural one (Yoon and Gurhan-Canli, 2004). In both cases, research suggests that consumers with differing thinking styles place different importance on contextual factors in considering or evaluating preferred products (Monga and John, 2008). In other words, analytic and holistic thinkers evaluate different parts or aspects of a product or brand. For instance, analytic thinkers place more importance on internal evaluations about products and their attributes (Monga and John, 2008; Nisbett et al., 2001). Since analytic thinkers are more object-centered (Jen and Lien, 2010), they tend to consider a product's attributes primarily and in isolation from its environment. They pay more attention to the analytic parts of the object, not to the whole. Thus, even when exposed to other information, such as product availability, company information, and so forth, analytic thinkers still first attend to product attributes (Liang, 2008). Moreover, they focus on their own inner evaluations and their cognitive evaluation of product attributes (Monga and John, 2008).

In contrast, holistic thinkers focus on context-dependent cognitive processes more than analytic thinkers (Jen and Lien, 2010). For holistic thinkers, although product attributes are important, other elements are as well, such as brand, reputation, and so forth in allowing one to come to a purchase decision (Liang, 2008). They focus on external cues and experiences more than analytic thinkers do (Nisbett et al., 2001), yet concurrently consider their own experiences (Nisbett et al., 2001). At the cultural level, studies have shown that Western consumers are more likely to make dispositional attributions and think that objects are independent of their environment and each other, which makes them think analytically. In contrast, Eastern consumers tend to make contextual attributions, for example every object in the environment is somehow interconnected, and thus it cannot be understood in isolation from its context (Choi et al., 2003; Liang, 2008).

Based on the differences outlined above, one would expect the influence of satisfaction and firm reputation on repurchase intention to differ among consumers employing different thinking styles. According to the disconfirmation of expectations paradigm, consumer satisfaction is the primary driver of consumer behavior. It is a function of cognitive evaluation of both expectations prior to consumption and actual experience, which are primarily based on product attributes. Satisfaction is internal and related to product attributes; therefore its influence on repurchase intention may be more powerful for analytic thinkers than for holistic ones.

On the other hand, customers form opinions about reputation based on direct experiences with the company or indirect, external sources, such as word of mouth, media interpretations, and so forth (Caruana and Ewing, 2009; Nguyen and LeBlanc, 2001; Shamma, 2012). Accordingly, reputation is conceptualized as "a socially shared impression" (Helm et al., 2010, p. 517). Moreover, as Balmer (2001) has stated, because reputation is linked with a firm's values, vision, and purpose, it can be expected to exert a broad influence over customers' evaluations. Thus, a company's reputation is accepted as an external information cue to forming attitudes about the firm (Bartikowksi et al., 2011; Bennett and Gabriel, 2001). A good reputation may create a halo effect, engendering a positive attitude toward service offerings (Byoungho et al., 2008). Consequently, for holistic thinkers, it may be assumed to be a more important factor affecting repurchase intention. 
As indicated before, we employed intra-cultural and cross-cultural analyses in this study. Assuming that the US and Turkey represent analytic and holistic cultures respectively, we proposed the following hypotheses for the cross-cultural comparison:

H1a: The predictive power of customer satisfaction on repurchase intention is stronger for the US sample, compared with the Turkish sample.

H1b: The predictive power of firm reputation on repurchase intention is stronger for the Turkish sample, compared with the US sample.

For intra-cultural analyses, we compared the analytic and holistic thinkers in terms of their repurchase intention, satisfaction and reputation evaluations. The following hypotheses were suggested:

$\mathrm{H} 2 \mathrm{a}$ : The predictive power of customer satisfaction on repurchase intention is stronger for analytic thinkers, compared with holistic thinkers.

$\mathrm{H} 2 \mathrm{~b}$ : The predictive power of firm reputation on repurchase intention is stronger for holistic thinkers, compared with analytic thinkers.

\section{DATA AND METHODS}

\subsection{Participants and Procedure}

Our study participants were mobile telecommunication service consumers. In many countries, the mobile telecommunication sector has grown rapidly over the last two decades and is seen as one of the most competitive sectors, with a high service-provider switching rate, compared with other service industries. Moreover, the sector's economic importance increases continuously. Today, consumers buy not only basic communication services but also navigators, computers, Internet access, and other multimedia applications. As a result, more research attention has been directed toward that sector, emphasizing that once customers connect with a particular service provider, their long-term retention with that same provider has particular ramifications for the company's success (Gerpott et al., 2001).

The hypotheses of this study were tested with data collected from the US sample and the Turkish sample. Both sets were composed of junior and senior undergraduate students attending large state universities in the two countries, who had been using mobile phone service providers' products. The data sets were collected during the same semester simultaneously. The reason for selecting undergraduate students was twofold. First, widespread usage of mobile phones among university students was thought to increase data validity and provide ease of data collection about mobile service providers. Second, evaluating university students regarding mobile service providers was not thought to be entirely different from evaluating users in the general public, given the nature of the questionnaire items.

After informing the students about the study's purpose and ensuring the answers' anonymity, participants were asked to fill out the questionnaire. For individuals in both the US sample and the Turkish sample, participation was voluntary. A convenience sampling technique was used to collect both sets of data. For the Turkish sample, the data were collected from the students who were present in classrooms. For the US sample, participants were invited to a research center to answer the questionnaire.

For the Turkish sample, to ensure the items' conceptual equivalence, the scale was translated into Turkish using a collaborative translation technique. The study's researchers translated the scale independently. Then, a professional translator fluent in both languages examined these two translations and the original scale to determine which of the two translations most closely captured the items' meanings. Based on suggestions and corrections made by this third party, the two researchers met again to resolve discrepancies in the Turkish version. Minor adjustments 
were made to increase the instrument's clarity. No adjustments were made to questionnaire items when collecting data from the US sample, given the results of previous studies regarding its reliability and validity (Choi et al., 2003; Cronin et al., 2000; Nguyen and LeBlanc, 2001; Oliver, 1980).

\subsection{Turkish Sample Characteristics}

A total of 250 questionnaire forms were distributed, with 185 questionnaires returned by respondents, constituting a $74 \%$ response rate. Before proceeding with hypothesis testing, missing values were replaced with mean values calculated for each variable. The total number of usable questionnaires remaining was 178. More than half the sample consisted of women (56\%) between the ages of 19 and 22 years. Most of the respondents (34.4\%) had been using mobile phones for between two to four years, while only $11 \%$ of them had been using phones for less than one year.

\subsection{The US Sample Characteristics}

A total of 300 questionnaire forms were distributed, with 215 questionnaires returned by respondents, constituting a $72 \%$ response rate. Following the same procedure as for the Turkish sample, before proceeding with hypothesis testing, missing values were replaced with mean values calculated for each variable. The total number of usable questionnaires remaining was 211 . The age of the US sample participants ranged from 18 to 23. Most of the respondents had been using mobile phones for between four to six years (35\%), followed by two to three years $(24.7 \%)$. The majority of the participants were Anglo-Saxon (81\%), and the remaining participants were either African American (9\%) or Hispanic (10\%).

\subsection{Measurement}

The questionnaire package consisted of five sections. Participants were asked to evaluate their mobile service provider. The first section included items about customer satisfaction. Satisfaction was measured with three items developed by Oliver (1980) and Cronin et al. (2000), with items intended to assess whether participants felt contented and pleased about the service provided by mobile phone service providers (e.g., "It was wise to use this service provider"). Respondents evaluated the items using a 5-point Likert-type scale, with answers ranging from "Strongly disagree" to "Strongly agree." The higher scores in this scale indicated the higher degree of satisfaction derived from the products of a particular service provider. In this study, reliability of the satisfaction items was found to be the same for the US sample and the Turkish sample (Cronbach's $\alpha=.89$ ) (see Appendix for scale items).

The second section was composed of three items developed by Nguyen and LeBlanc (2001). These items measured the firm's perceived standing and status (i.e., mobile service providers, particularly) in the minds of customers. As in satisfaction, firm reputation was measured with a 5-point agreement scale in which higher scores indicated higher levels of perceived reputation. Reliability of the reputation items was found to be .77 for the United States; .79 for Turkey.

The third section included three items concerning repurchase intention. The items were developed by Cronin et al. (2000) to measure a customer's inclination to use the products or services of a particular firm if they were to make the same purchase again. Participants responded using the 5-point Likert-type scale; answers ranged from "Too low" to "Too high," with high scores indicating a higher level of repurchase intention. Reliability of the repurchase intention items was found to be satisfactory (Cronbach's $\alpha=.92$ for the US sample; $\alpha=.91$ for the Turkish sample). 
Another important variable - thinking style - was presented in the fourth section of the questionnaire form. Developed by Choi et al., (2003), eight items were intended to measure a participant's thinking style when evaluating things situated, and events happening, around them. Using the 5-point Likert-type scale, higher scores suggested the existence of a holistic thinking style. Reliability estimates for the thinking-style scale were .75 for the US sample; .82 for the Turkish sample.

The last section included items related to demographic information, such as gender and age, as well as general questions, such as the service provider's name and the duration of using that particular service provider.

\section{RESULTS}

\subsection{Preliminary Analysis}

Before testing the roles of customer satisfaction and reputation in repurchase intention for our two samples, we needed to determine whether instruments designed to measure the aforementioned variables (i.e., customer satisfaction, reputation, and repurchase intention) were cross-culturally invariant. In cross-cultural studies, the test of measurement invariance (i.e., metric variance) was suggested. As Steenkamp and Baumgartner (1998) point out, a multigroup, confirmatory factor analysis model is the most powerful and versatile way of testing for the cross-cultural invariance.

Following the suggestions of Jöreskog (1971), first, the pattern of factor loadings for each observed variable was tested for equivalence across the US sample and the Turkish sample using Analysis of Moment Structures (AMOS 17) (Arbuckle, 2008). However, the issue of measurement invariance is not addressed separately but rather tested as part of the test of hypotheses. Since the hypothesized model includes both measurement and structural models, it allows for a simultaneous assessment of measurement and relational invariance. For both of our samples, three latent variables (customer satisfaction, firm reputation, and repurchase intention) were hypothesized to be measured with three indicator variables, and these latent variables were not allowed to covary. The baseline model is shown in Figure 1.

Figure 1

Baseline Model

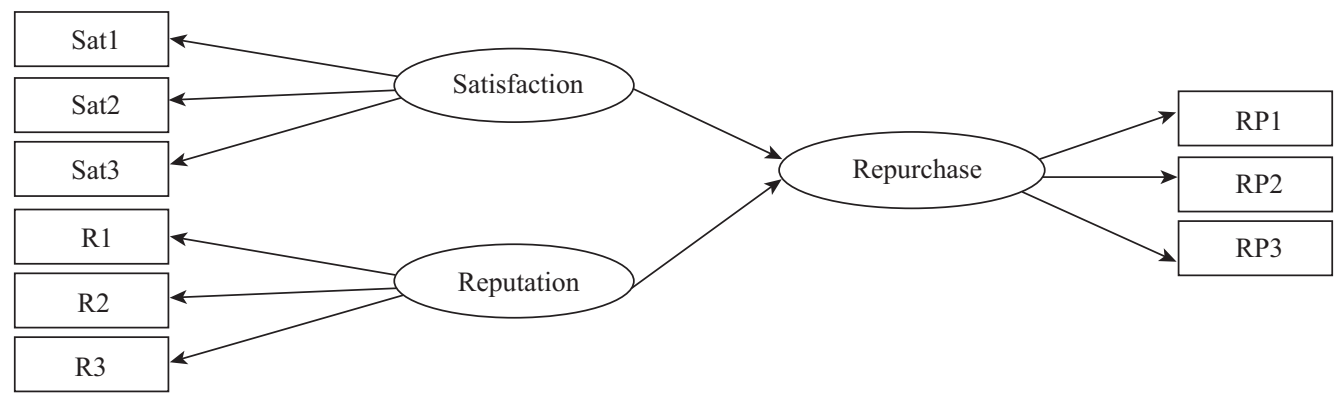

Note: Sat: Satisfaction items, $R=$ Reputation items, RP: Repurchase itention items.

\subsection{Analysis and Results for Cross-Cultural Comparison}

After demonstrating measurement invariance, we tested the validity of our assumption that US participants would be more likely to use an analytic thinking style; whereas Turkish participants would use a holistic thinking style. The independent sample $t$-test results validated our assumption in that the mean score of thinking-style items was found to be higher in the Turkish sample $(M=3.98)$, compared with the US sample $(M=3.54) ; t(392)=7.57 ; p<.01)$. 
This result suggested that the Turkish sample demonstrated a holistic-thinking tendency. As for the other study variables, the mean of satisfaction was found to be 3.68 for the Turkish sample and 3.88 for the US sample. The mean of firm reputation turned out to be 3.52 for Turkish respondents and 3.87 for the US sample.

After testing the aforementioned assumption, we tested the validity of the hypothesized model for the US sample and the Turkish sample using multigroup, full-latent variable modeling. Maximum likelihood estimation was employed, given the existence of multivariate normality among variables. As expected, customer satisfaction and firm reputation both predicted repurchase intention. However, before evaluating the magnitude of the relationships among variables, first, the hypothesized model's invariance was assessed using the nested model comparison method. First, the unconstrained model was compared with Model 1 in which all factor loadings were constrained to be equal across both samples. A $\chi 2$ difference test suggested the existence of measurement invariance across two samples, which was in parallel with the results obtained in our preliminary analysis $(\Delta \chi 2(6)=10.322 ; p>.05)$. Once the measurement invariance model (Model 1) was accepted, more restrictive Model 2, in which both factor loadings and structural weights were constrained to be equal, was compared with Model 1. Again, the $\chi 2$ difference test suggested the existence of invariance across two samples $(\Delta \chi 2(6)=5.178 ; p>.05)$. This result indicated the similarity of the hypothesized paths from customer satisfaction and firm reputation to repurchase intention. In other words, the paths from satisfaction and firm reputation to repurchase intention were almost equal in magnitude for both samples. After demonstrating the hypothesized paths' invariance, more restrictive Model 3 was specified. In Model 3, structural covariances between customer satisfaction and reputation were assumed to be equal. The nested model comparison, however, yielded a significant $\chi 2$ difference value, meaning that the magnitude of the relationship between satisfaction and reputation differed across two samples $(\Delta \chi 2(3)=26$; $p>.05)$. Since invariance was not found with respect to structural covariances, more restrictive models were not compared. The nested model comparison suggested the existence of structural and measurement invariance, though it acknowledged the differences with respect to structural covariances.

After nested model comparisons, the fit between data and models was assessed using several indices. As can be seen in Table 1, the fit between data and models deteriorated as more restrictive models were utilized, but this deterioration was not considerable. The fit indices for Model 2, which suggested the existence of measurement and structural invariance, indicated a relatively well-fitting model, based on the criteria suggested by Hu and Bentler (1999).

Table 1

Fit Indices of Cross Cultural Comparison Models

\begin{tabular}{lc|c|cc|c} 
& $\chi 2$ & df & GFI & NFI & RMSEA \\
\hline Unconstrained model & 130.49 & 44 & .93 & .96 & .07 \\
\hline $\begin{array}{l}\text { Model 1 } \\
\text { (measurement weights constrained) }\end{array}$ & 140.81 & 52 & .93 & .95 & .07 \\
\hline $\begin{array}{l}\text { Model 2 } \\
\text { (Structural weights constrained) }\end{array}$ & 145.99 & 54 & .92 & .95 & .07 \\
\hline $\begin{array}{l}\text { Model 3 } \\
\text { (Structural covariances constrained) }\end{array}$ & 172.92 & 57 & .01 & .94 & .07
\end{tabular}

When parameters of the unconstrained model were examined, all of the factor loadings and structural weights were found to be significant for both samples. As can be seen in Table 2, measurement weights were similar across the two samples. Although the difference was not significant, the path from satisfaction to repurchase intention was stronger in the Turkish sample, 
compared with the US one, while the path from reputation to repurchase intention was stronger in the US sample. In the two samples, both customer satisfaction (the US sample, $\beta=.46 ; p<.05$; the Turkish sample, $\beta=.52 ; p<.05$ ) and firm reputation (the US sample, $\beta=.46 ; p<.05$; the Turkish sample, $\beta=.36 ; p<.05)$ predicted repurchase intention.

Table 2

Results of the Path Analysis: Parameter Estimates

\begin{tabular}{|c|c|c|c|c|c|c|}
\hline \multirow{2}{*}{ Paths from } & \multicolumn{3}{|c|}{ USA } & \multicolumn{3}{|c|}{ Turkey } \\
\hline & B & SE B & $\beta$ & B & SE B & $\beta$ \\
\hline Satisfaction to S1 & 1.00 & -- & $.92 * *$ & 1.00 & -- & $.94 * *$ \\
\hline Satisfaction to S2 & 1.00 & .04 & $.94 * *$ & .92 & .04 & $.95 * *$ \\
\hline Satisfaction to S3 & .98 & .07 & $.75 * *$ & .77 & .06 & $.72 * *$ \\
\hline Reputation to R1 & 1.00 & -- & $.66^{* *}$ & 1.00 & -- & $.78 * *$ \\
\hline Reputation to R2 & .86 & .10 & $.76^{* *}$ & 1.04 & .11 & $.82 * *$ \\
\hline Reputation to R3 & 1.22 & .13 & $.84 * *$ & 1.14 & .13 & $.82 * *$ \\
\hline R.Purc int to RPI1 & 1.00 & -- & $.87 * *$ & 1.00 & -- & $.85^{* *}$ \\
\hline R.Purc int to RPI2 & 1.22 & .06 & $.88 * *$ & 1.18 & .07 & $.91 * *$ \\
\hline R.Purc int to RPI3 & 1.17 & .06 & $.93 * *$ & 1.23 & .08 & $.91 * *$ \\
\hline Satisfaction to R.Purch int & .44 & .11 & $.46^{* *}$ & .43 & .07 & $.52 * *$ \\
\hline Reputation to R. Purch int & .56 & .16 & $.46 * *$ & .35 & .09 & $.36^{* *}$ \\
\hline
\end{tabular}

Note: $* * \mathrm{p}<.01$

We proposed that the predictive power of satisfaction on repurchase intention would be stronger for the US sample (H1a); whereas the predictive power of firm reputation on repurchase intention would be stronger for the Turkish sample (H1b). However, the findings failed to provide support for $\mathrm{H} 1 \mathrm{a}$ and $\mathrm{H} 1 \mathrm{~b}$. In the US sample, satisfaction and reputation exhibited the same level of importance for repurchase intention. Considering the results of the cross-cultural analyses, it is hard to conclude that thinking style plays a role in the relationship among satisfaction, reputation, and repurchase intention at the cultural level. Accordingly, thinking style should not be regarded as a cultural difference variable. Although we obtained contradictory results, we once again demonstrated the importance of customer satisfaction and firm reputation for repurchase intention for two different societies.

\subsection{Analysis and Results for Intra-Cultural Comparison}

\subsubsection{The US sample}

For intra-cultural analyses, we examined relational equivalence across different thinking styles by constraining structural equations models to be equivalent across holistic and analytic thinker data sets. As stated previously, we expected that firm reputation and customer satisfaction would predict repurchase intention differently in the two thinking styles. Thus, we hypothesized that the addition of the equality constraints for structural paths would create a significant decrement in fit, leading us to conclude that the model's structural properties differ between the two thinking styles.

Data collected from the US sample were prepared before testing the hypotheses. For this, the mean score for the thinking-style scale was calculated for each participant. Then, based on the median score of these mean scores, participants were split into two groups, with 91 participants in 
analytic thinking and 120 participants in holistic thinking. Participants in these two groups were similar in terms of age and gender.

The hypothesized model examined the predictors of repurchase intention for customers with different thinking styles. It was assumed that two latent variables - customer satisfaction (with three indicators) and firm reputation (also with three indicators) - would predict repurchase intention differently for holistic and analytic thinkers. Multigroup, full-latent variable modeling was employed using AMOS 17 (Arbuckle, 2008). In this analysis, five models were specified: In the first (Model 1), factor loadings; the second (Model 2), structural weights (in addition to factor loadings); the third (Model 3), structural covariances (in addition to factor loadings and structural weights); the fourth (Model 4), structural residuals (in addition to factor loadings, structural weights, and covariances); and in the final model (Model 5), all parameters were constrained to be equal across the two groups.

While the chi-square of the unconstrained model was 117.43 with 48 degrees of freedom, for Model 1, it was 130.35 with 54 degrees of freedom. Thus, the factor-loading constraints increased the chi-square by 12.92 for six degrees of freedom, which was not significant at the .01 level. This suggested the existence of metric variance (i.e., measurement variance). Thus, we continued nested model comparisons by comparing Model 1 with Model 2. Examining several fit indices (Goodness of Fit Index [GFI], Normed Fit Index [NFI], and Root Mean Square Error of Approximation [RMSEA]) and the chi-square difference $\left(\Delta \chi^{2}\right)$ test, the equality constraint caused a moderate decrement in fit (see Table 3$)$. A change in $\chi^{2}(\Delta \chi 2=6.67 ; p>.01)$ was insignificant at the .01 significance level yet significant at a more liberal significance level (.05), suggesting relational invariance to a certain extent, contrary to our expectations.

Table 3

The US Sample: Fit Indices of Invariance Models

\begin{tabular}{lcc|c|c|c|c} 
& $\chi 2$ & df & $\Delta \chi 2 / \Delta d f$ & CFI & NFI & RMSEA(CI) \\
\hline Unconstrained Model & 117.43 & 48 & 2.45 & .96 & .93 & $.08(.06, .10)$ \\
Model 1 & 130.35 & 54 & 2.41 & .95 & .92 & $.08(.06, .10)$ \\
\hline Model 2 & 137.02 & 56 & 2.45 & .95 & .92 & $.08(.07, .10)$ \\
Model 3 & 137.52 & 59 & 2.33 & .95 & .92 & $.08(.06, .09)$ \\
\hline Model 4 & 143.94 & 60 & 2.40 & .95 & .91 & $.08(.06,10)$ \\
\hline Model 5 & 160.51 & 69 & 2.33 & .94 & .90 & $.08(.06, .10)$
\end{tabular}

Despite feeling somewhat unsure about this relational invariance, we continued with our nested comparisons, comparing Model 3 with Model 2. For this test, the change in $\chi 2(\Delta \chi 2=.50$; $p>.01$ ) was insignificant at both the .01 and .05 significance levels, leading us to conclude that structural covariances (covariances among satisfaction and firm reputation) were similar across the two groups. When we compared Models 4 and 3, we observed moderate deterioration, as evidenced by increased $\chi^{2}$ ( $\chi 2$ value rose from 137.52 to $143.94 ; \Delta \chi 2=6.42 ; p<.01$ ). This suggested a lack of invariance across the two groups in terms of structural residuals. Since it is difficult to establish, the lack of invariance in structural and measurement residuals is not generally considered to be necessary for multigroup comparisons. Thus, a lack of invariance in these parameters was ignored in this study.

Nested model comparisons suggested the existence of relational invariance to a certain extent. Therefore, our expectations regarding the differences between thinking styles seemed to be refuted. Given the conflicting conclusions that could be reached with different significance levels, however, fit indices and parameter estimates were examined closely. The fit indices of Models 2 and 3 indicated the existence of acceptable models, according to criteria suggested by $\mathrm{Hu}$ and 
Bentler (1998). When parameters of the constrained model (Model 3) were investigated (see Table 4), we observed that the path from satisfaction to repurchase intention was significant for both analytic $(\beta=.40 ; p<.05)$ and holistic thinkers $(\beta=.36 ; p<.05)$. The same was also true for the path from reputation to repurchase intention. This path was again significant across the two samples (for analytic thinkers, $\beta=.58 ; p<.05$; for holistic thinkers, $\beta=.53 ; p<.05$ ).

Table 4

The US Sample: Results of the Path Analysis

\begin{tabular}{|c|c|c|}
\hline \multirow{2}{*}{ Paths from } & Holistic & Analytic \\
\hline & $\beta$ & $\beta$ \\
\hline Satisfaction to S1 & $.93 * *$ & $.90 * *$ \\
\hline Satisfaction to S2 & $.94 * *$ & $.97 * *$ \\
\hline Satisfaction to S3 & $.71 * *$ & $.79 * *$ \\
\hline Reputation to R1 & $.61 * *$ & $.69^{* *}$ \\
\hline Reputation to R2 & $.74 * *$ & $.80 * *$ \\
\hline Reputation to R3 & $.83 * *$ & $.80 * *$ \\
\hline R.Purc int to RPI1 & $.88^{* *}$ & $.86^{* *}$ \\
\hline R.Purc int to RPI2 & $.89 * *$ & $.88 * *$ \\
\hline R.Purc int to RPI3 & $.96 * *$ & $.91 * *$ \\
\hline Satisfaction to R.Purch int & $.34 * *$ & $.38 * *$ \\
\hline Reputation to R. Purch int & $.54 * *$ & $.60 * *$ \\
\hline
\end{tabular}

Note: $* * \mathrm{p}<.01$

These findings indicated that the predictive power of satisfaction on repurchase intention was stronger in the analytic thinkers' sample, compared with that of the holistic thinkers. This supported H2a. However, quite unexpectedly, the impact of reputation on repurchase intention was also a bit stronger among analytic thinkers, compared with holistic thinkers. Consequently, $\mathrm{H} 2 \mathrm{~b}$ is not supported.

These unexpected results led us to conduct additional analyses. First, independent sample $t$-tests were conducted to compare customer satisfaction, firm reputation, and repurchase intention for holistic and analytic thinking groups. We found no significant difference in the repurchase intention scores for analytic thinkers $(M=3.86, S D=.80)$ and holistic thinkers $(M=3.92$, $S D=.84) ; t(205)=-.58, p=.56)$. For customer satisfaction, the mean scores of analytic thinkers $(M=3.85, S D=.68)$ were quite similar to those of holistic thinkers $(M=3.82, S D=.73)$, $t(205)=-.53, p=.60)$. For reputation, mean scores were again quite similar for the two groups (analytic thinkers, $M=3.94, S D=.89$; holistic thinkers, $M=4.01, S D=.83$, with $t(205)=-.77$, $p=.44)$. The results suggested there were no remarkable differences with respect to repurchase intention and its predictors across the two thinking styles. We do believe, however, that the range restriction in the US data could have affected our results and dampened the customer satisfaction effect when firm reputation was included in the model.

\subsubsection{The Turkish Sample}

As in the previous section, we examined relational equivalence across different thinking styles by constraining structural equations models to be equivalent across holistic and analytic thinker data sets collected from Turkey. Again, the data were prepared before testing the hypotheses. For this reason, the mean score for the thinking-style scale was calculated for each participant. Next, 
based on the median value of these mean scores, participants were split into two groups, with 80 participants in analytic thinking and 98 participants in holistic thinking. Participants in these two groups were similar in terms of demographic characteristics, such as age and gender.

Multigroup, full-latent variable modeling was employed to test the model proposed in the cross-cultural comparison. In this particular model, again, customer satisfaction and firm reputation were proposed to predict repurchase intention. Five models were specified (see the above section on the US sample for details of these models) and again, first measurement invariance, then relational invariance was assessed with nested model comparisons.

The chi-square of the unconstrained model was 80.46 with 46 degrees of freedom, while for Model 1, it was 89.47 with 54 degrees of freedom. Constraining the factor loadings increased the chi-square by 9.01 for six degrees of freedom, yet this increase was insignificant $(p>.01)$. This suggested the existence of measurement variance across the two thinking styles. After demonstrating measurement invariance, we continued with nested model comparisons by comparing Model 1 with Model 2. Looking at several fit indices (GFI, NFI, and RMSEA) and the chi-square difference $\left(\Delta \chi^{2}\right)$ test, the equality constraint for structural weights caused a moderate decrement in fit (see Table 5). Remarkably, change in $\chi^{2}\left(\Delta \chi^{2}=7.39\right)$ was significant at the .01 significance level, suggesting that hypothesized relations differed across the two samples. Given the lack of relational invariance, we made no further nested comparisons and concluded that the relationship among customer satisfaction, firm reputation, and repurchase intention differed with respect to different thinking styles.

Table 5

The Turkish Sample: Fit Indices of Invariance Models

\begin{tabular}{lcc|cc|c|c|} 
& $\chi 2$ & df & $\Delta \chi 2 / \Delta \mathbf{d f}$ & CFI & NFI & RMSEA (CI) \\
Unconstrained Model & 80.46 & 48 & 1.75 & .97 & .94 & $.07(.04, .08)$ \\
Model 1 & 89.47 & 54 & 1.66 & .97 & .93 & $.06(.04, .08)$ \\
Model 2 & 96.86 & 56 & 1.73 & .97 & .93 & $.06(.04, .09)$ \\
Model 3 & 106.15 & 57 & 1.86 & .96 & .92 & $.07(.05, .09)$ \\
Model 4 & 107.98 & 58 & 1.86 & .96 & .92 & $.07(.05,09)$ \\
Model 5 & 123.92 & 67 & 1.85 & .95 & .91 & $.07(.05, .09)$
\end{tabular}

To examine these differences further, we analyzed both unstandardized and standardized path estimates. When parameters of the unconstrained model (Model 1) were investigated (see Table 6), we observed that the path from satisfaction to repurchase intention was significant for both holistic $(\beta=.41 ; p<.05)$ and analytic thinkers $(\beta=.86 ; p<.05)$. However, the same was not true for the path from reputation to repurchase intention. This path was significant for holistic thinkers $(\beta=.48 ; p<.05)$ but not significant for analytic thinkers $(\beta=.01 ; p>.05)$. 
Table 6

The Turkish Sample: Results of the Path Analysis

\begin{tabular}{|c|c|c|}
\hline \multirow{2}{*}{ Paths from } & Holistic & Analytic \\
\hline & $\beta$ & $\beta$ \\
\hline Satisfaction to S1 & $.94 * *$ & $.92 * *$ \\
\hline Satisfaction to S2 & $.98 * *$ & $.91 * *$ \\
\hline Satisfaction to S3 & $.66^{* *}$ & $.78 * *$ \\
\hline Reputation to R1 & $.87 * *$ & $.68 * *$ \\
\hline Reputation to R2 & $.80 * *$ & $.81 * *$ \\
\hline Reputation to R3 & $.79 * *$ & $.86^{* *}$ \\
\hline R.Purc int to RPI1 & $.84 * *$ & $.86^{* *}$ \\
\hline R.Purc int to RPI2 & $.91 * *$ & $.91 * *$ \\
\hline R.Purc int to RPI3 & $.92 * *$ & $.90 * *$ \\
\hline Satisfaction to R.Purch int & $.41 * *$ & $.86^{* *}$ \\
\hline Reputation to R. Purch int & $.48 * *$ & .01 \\
\hline
\end{tabular}

Note: $* * \mathrm{p}<.01$

These findings indicated that the influence of satisfaction and reputation on repurchase intention varies among analytic and holistic thinkers. As expected, reputation's impact on repurchase intention was stronger, relative to satisfaction's impact among holistic thinkers. Also, satisfaction is more important for analytic thinkers than it is for holistic ones. These findings provided support for both $\mathrm{H} 2 \mathrm{a}$ and $\mathrm{H} 2 \mathrm{~b}$. Although we could not find support in the cultural-level analysis, intra-cultural analyses provided empirical support for our hypotheses for the Turkish sample.

\section{DISCUSSION AND CONCLUSION}

This study aims to determine whether the influence of satisfaction and reputation on repurchase intention varies among analytic and holistic thinkers. Across testings involving an individual approach to the cross-cultural comparison, we provide empirical evidence that the consumer's evaluation of repurchase intention and its antecedents differ according to individuals' thinking styles. Table 7 summarizes the findings of cross-cultural and intra-cultural comparisons. 
Table 7

Summary of the Findings
Results
Hypothesis
Cross Cultural Comparison
(USA versus Turkey)

H1a: The predictive power of customer satisfaction on repurchase intention is stronger for the US sample compared to the Turkish sample.

Not supported

$\mathrm{H} 1 \mathrm{~b}$ : The predictive power of firm reputation on repurchase intention is stronger for the Turkish sample compared to the US sample.

Not supported

Intra-Cultural Comparison Intra-Cultural

(US) Comparison (Turkey)

$\mathrm{H} 2 \mathrm{a}$ : The predictive power of customer satisfaction on repurchase intention is stronger for analytic thinkers compared to holistic thinkers.

Supported

Supported

$\mathrm{H} 2 \mathrm{~b}$ : The predictive power of firm reputation on repurchase intention is stronger for holistic thinkers compared to analytic Not supported thinkers.

As can be observed in Table 7, the results of our individual approach to the cross-cultural comparison are not supported, but we did find support in the individual base within each culture. Specifically, holistic or analytic thinking styles create a difference at the individual level (within culture) but not at the cultural level (cross-culture). In this study, we regarded thinking style as a cultural difference variable and assumed that the US and Turkish samples predisposed people to adopt analytic and holistic thinking styles, respectively. Although this assumption was substantiated with statistical tests, it is possible to rule out the effects of education, acculturation, and other confounding variables that cause within-country variance to be greater than betweencountry variance. The predictive power of satisfaction was found to be stronger than that of reputation in the whole Turkish sample whereas the opposite result was obtained in the intracultural comparison, conducted with the same sample. This conflicting result may arise from within- and between-variance differences. Cross-cultural analyses tested for hypothesized relations by aggregating reputation, satisfaction, and repurchase intention scores obtained from the US and Turkish samples, without taking into account the effect of a holistic thinking style. Intra-cultural analyses, however, tested for the same hypothesized relations for holistic and analytic thinkers only for the Turkish sample. This design enabled us to consider both thinkingstyle effects and within-group variance for all variables in the study. On the other hand, crosscultural analyses were based on the assumption that holistic and analytic thinking styles are peculiar to Turkish and US cultures, respectively, without accounting for a within-group variance in thinking style. Variability within the Turkish culture could be higher than variability between the cultures of Turkey and the United States, and this could have resulted in our reaching different conclusions when we tested the same hypotheses with different designs.

The alternative explanation for this conflicting result could be related to the measurement of thinking style. Although thinking style is argued to be a cultural difference, it could be conceptualized as an individual difference variable as well. Buchtel and Norenzayan (2008) claim that holistic thinking can be developed, learned, and trained. For example, exposure to Western-style formal education in non-Western cultures increases the tendency to decontextualize deductive arguments (Cole and Scribner, 1974), thereby leading non-Westerners to use an analytic thinking style. In other words, people may adopt an analytic thinking style, even if they were born and raised in an Eastern or other culture or vice versa. 
Thus, this result may provide additional insight into the literature: Although thinking styles emerge from differences in social environments across cultures, it is also the case that social environments can vary within a culture, causing variations in thinking styles (Choi et al., 2007). Therefore, a thinking style can be considered as an individual difference variable. This conclusion also supports previous studies focusing on thinking style as a mechanism for understanding individual differences within culture (Monga and John, 2008).

Our intra-cultural analyses provide empirical evidence for using thinking style as an individual difference variable. As such, individuals who use an analytic thinking style are more affected by postpurchase satisfaction evaluations while making their repurchase decision than holistic thinkers are. In addition, for the Turkish sample, as we hypothesized, the predictive power of firm reputation on repurchase intention is stronger for holistic thinkers, compared with analytic thinkers. These results support the relevant literature that notes that analytic thinkers focus on their internal evaluations of product attributes in making a decision (Monga and John, 2008), while holistic thinkers need more external evaluations, based on brand, reputation, or convenience, in addition to internal evaluations (Liang, 2008; Nisbett et al., 2001).

Results of this study provide empirical implications for marketing managers. First, consumers may not demonstrate evidence of both internal (cognitive, e.g., customer satisfaction) and external (emotional, e.g., firm reputation) evaluations in their purchasing and retention decisions. In other words, some consumers (e.g., analytics) prioritize internal and cognitive evaluations, while others (e.g., holistics) use primarily external and emotional evaluations to make their decisions. Marketing managers would do well to consider thinking style differences while developing their marketing strategies. Since thinking style as such can be changed and learned over time (Buchtel and Norenzayan, 2008), with the influence of social environmental changes, marketers can employ promotional tools to encourage consumers to think holistically. As in our example, mobile phone service providers and marketing firms, in general, can benefit more from their positive reputations by following promotional strategies that focus on changing consumers' thinking style and encourage them to think holistically. In doing so, firms can use their reputation as a buffer against negative consumer responses and possibly reduce the potential negative effects of dissatisfaction in a service failure situation. Marketers can enlighten their customers regarding the importance of both internal and external evaluation factors and can highlight the role the context plays, as well as situational factors while customers are evaluating a service or brand.

Finally, consumers who exhibit a different thinking style can be treated as a market segment whereby thinking style's potential as an influence on many aspects of consumer behavior is considered. At this point and depending on our results, using thinking style as an individual, rather than cultural, segmentation base may be a more effective strategy that can highlight the importance of local marketing strategies, instead of global ones.

\section{LIMITATIONS AND SUGGESTIONS FOR FUTURE RESEARCH}

The limitations of the aforementioned studies should be acknowledged simultaneously with interpreting the findings and setting the direction for future research. One limitation relates to the existence of confounding variables. This study revealed the effects of thinking style, firm reputation, and satisfaction on repurchase intention. Yet consumers' thinking styles may change the effects of individual or situational factors, as they concern repurchase intention. For example, holistic thinkers may use perceived value as an antecedent of repurchase behavior more so than analytic thinkers, since perceived value contains numerous situational and contextual evaluation factors. Future studies should take into account the thinking style effect on other antecedents of repurchase behavior, such as perceived value and service quality. 
As indicated above, data were collected from students and were studied as if they reflected characteristics of all mobile phone users, in general. Although university students are heavy users of mobile phones, collecting data solely from them does cast doubt on the results' generalizability. Therefore, we advise researchers to replicate this study using a more diverse customer sample that incorporates different product and service industries.

It is also noteworthy to acknowledge that US respondents had been using mobile phones for longer period of time compared to Turkish respondents. Albeit customer satisfaction and firm reputation could be affected by the years of experience, the differences are not expected to be substantial as evidenced by relatively close mean scores of study variables (see Analysis and Results for Cross-Cultural Comparison section).

Despite the limitations listed above, this study addressed shortcomings in the literature by demonstrating a thinking style's impact on repurchase intention via its effects on firm reputation and satisfaction. To the best of our knowledge, no prior studies have investigated this issue thus far. Our results demonstrated the importance of national culture in shaping thinking style, and thereby, consumption habits.

\section{References}

Agustin, C. and Singh, J. (2005). Curvilinear effects of consumer loyalty determinants in relational exchange. Journal of Marketing Research, 42(1), 96-108. doi: http://dx.doi.org/10.1509/jmkr.42.1.96.56961.

Arbuckle, J. (2008). Amos 17.0 User's Guide. Amos Development Corporation. Spring House, PA: Spring House.

Ajzen, I. (2011). The theory of planned behaviour: Reactions and reflection. Psychology \& Health, 26(9), $1113-1127$. doi: 10.1080/08870446.2011.613995.

Anderson, E.W. and Sullivan, M.W. (1993). The antecedents and consequences of customer satisfaction for firm. Marketing Science, 12(2), 125-143. doi:10.1287/mksc.12.2.125.

Aydin, S., Özer, G. and Arasil, Ö. (2005). Customer loyalty and the effect of switching costs as a moderator variable: A case in the Turkish mobile phone market. Marketing Intelligence \& Planning, 23(1), 89-103. doi: $10.1108 / 02634500510577492$.

Balmer, J.M.T. (2001). Corporate identity, corporate branding and corporate marketing Seeing through the fog. European Journal of Marketing, 35(3/4), 248-291. doi: 10.1108/03090560110694763.

Bartikowski, B., Walsh, G. and Beatty, S.E. (2011). Culture and age as moderators in the corporate reputation and loyalty relationship. Journal of Business Research, 64, 966-972. doi: 10.1016/j.jbusres.2010.11.019.

Bennett, R. and Gabriel, H. (2001). Reputation, trust and supplier commitment: The case of shipping company/ seaport relation. Journal of Business \& Industrial Marketing, 16(6), doi: 10.1108/EUM0000000006018.

Berry, J.W. and Dasen, P.R. (Eds.) (1974). Culture and cognition. London: Methuen.

Bloemer, J. and De Ruyter, K. (1998). On the relationship between store image, store satisfaction and store loyalty. European Journal of Marketing, 32(5/6), 499-513. doi: 10.1108/03090569810216118.

Bloemer, J.M. and Kasper, H.D.P. (1995). The complex relationship between consumer satisfaction and brand loyalty. Journal of Economic Psychology, 16(2), 311-329. http://www.sciencedirect.com/science/article/ pii/016748709500007B.

Bolton, R.N. and Drew, J.H. (1991). Multistage model of customers' assessments of service quality and value. Journal Of Consumer Research, 17 (March), 375-384. http://www.jstor.org/stable/2626833.

Brady, M.K., Knight, G.A., Cronin, J.J., Hult, T.G. and Keillor, B.D. (2005). Removing the contextual lens: A multinational, multi-setting comparison of service evaluation model. Journal of Retailing, 81(3), 215-230. doi: http://dx.doi.org/10.1016/j.jretai.2005.07.005

Buchtel, E.E. and Norenzayan, A. (2009). Thinking across cultures: Implications for dual processes. In: J. Evans and K. Frankish (Eds.), In two minds: Dual processes and beyond (pp. 217-238). Oxford: Oxford University Press.

Burroughs, J.E. (1996). Product symbolism, self meaning, and holistic matching: The role of information processing in impulsive buying. In: K.P. Corfman and J.G. Lynch Jr. (Eds.), NA - Advances in Consumer Research 23 (pp. 463-469). Provo, UT: Association for Consumer Research. http://www.acrwebsite.org/search/viewconference-proceedings.aspx? Id=7874.

Byoungho, J., Yong, P.J. and Jiyoung, K. (2008). Cross-cultural examination of the relationships among firm reputation, e-satisfaction, e-trust, and e-loyalty. International Marketing Review, 25(3), 324-337. doi: 10.1108/02651330810877243. 
Caruana, A. and Ewing, M.T. (2009). How corporate reputation, quality, and value influence online loyalty. Journal of Business Research, 63(9-10), 1103-1110. doi:10.1016/j.jbusre 2009.04.030.

Chaiken, S. (1980). Heuristic versus systematic information processing and the use of source versus attribute cues in persuasion. Journal of Personality and Social Psychology, 39 (November), 752-66.

Chang, T-Z. and Wildt, A.R. (1994). Price, product information, and purchase intention: An empirical study. Journal of the Academy of Marketing Science, 22(1), 16-27. doi: 10.1177/0092070394221002.

Chen, C.-F. and Tsai, M.-H. (2008). Perceived value, satisfaction, and loyalty of TV travel product shopping: Involvement as a moderator. Tourism Management 29(6), 1166-1171. http://www.sciencedirect.com/science/ article/pii/S026151770800040X.

Choi, K-S., Cho, W.-H., Lee, S., Lee, H. and Kim, C. (2004). The relationships among quality, value, satisfaction and behavioral intention in health care provider choice: A South Korean study. Journal of Business Research, 57(8), 913-921. doi: 10.1177/0146167206298568.

Choi, I., Dalal R., Kim-Prieto, C. and Park, H. (2003). Culture and judgment of causal relevance. Journal of Personality and Social Psychology, 84(1), 46-59. doi: 10.1037/0022-3514.84.1.46.

Choi, I., Koo, M. and Choi, J.A. (2007). Individual differences in analytic versus holistic thinking. Pers Soc Psychol Bull, 33(5), 691-705. doi: 10.1177/0146167206298568.

Cole, M. and Scribner, S. (1974) Culture and thought; A psychological introduction. New York and Chichester, England: Wiley.

Cretu, A.E. and Brodie, R.J. (2007). The influence of brand image and company reputation where manufacturers market to small firms: A customer value perspective. Industrial Marketing Management, 36, 230-240. doi: http://dx.doi.org/10.1016/j.indmarman.2005.08.013.

Cronin, J.J., Brady, M.K. and Hult, G.T. (2000). Assessing the effects of quality, value, and customer satisfaction on consumer behavioral intentions in service environment. Journal of Retailing, 76(2), 193-218.

Dong, S., Ding, M., Grewal, R. and Zhao, P. (2011). Functional forms of the satisfaction-loyalty relationship. International Journal of Research in Marketing, 28(1), 38-50. doi:10.1016/j.ijresmar.2010.09.002.

Dube, L. and Scmitt, B.H. (1991). The processing of emotional and cognitive aspects of product usage in satisfaction judgments. In: R. H. Holman and M. R. Solomon (Eds.), NA-Advances in Consumer Research Volume 18 (pp. 52-56). Provo, UT: Association for Consumer Research.

Hall, E.T. (1976). Beyond Culture. Garden City, NY: Anchor.

Hellier, P.K., Geursen, G.M., Carr, R.A. and Rickard, J.A. (2003). Customer repurchase intention: A general structural equation model. European Journal of Marketing, 37(11/12), 1762-1800. doi 10.1108/03090560310495456.

Helm, S., Eggert, A. and Garnefeld, I. (2010). Modelling the impact of corporate reputation on customer satisfaction and loyalty using PL. In: V. Esposito Vinzi, W. Chin, J. Henseler and H. Wang (Eds.), Handbook of partial least squares: Concepts, methods and applications in marketing and related fields, Springer Handbooks of Computational Statistics Series (pp. 691-711). Berlin/Heidelberg: Springer.

Hofstede, G. (2001). Culture's consequences: Comparing values, behaviors, institutions and organizations across nations. California: Sage Publications.

Homburg, C. and Giering, A. (2001). Personal characteristics as moderators of the relationship between customer satisfaction and loyalty - an empirical analysis. Psychology \& Marketing, 18(1), 43-66. http://dx.doi. org/10.1002/1520-6793(200101)18:1<43::AID-MAR3>3.0.CO;2-I.

Hutchinson, J.W. and Alba, J.W. (1991). Ignoring irrelevant information: situational determinants of consumer learning. Journal of Consumer Research, 18(3), 325-345. http://www.jstor.org/stable/2489343.

$\mathrm{Hu}$, L. and Bentler, P.M. (1999). Cutoff criteria for fit indexes in covariance structure analysis: Conventional criteria versus new alternatives. Structural Equation Modeling, 6(1), 1-55. doi:10.1080/10705519909540118.

Gerpott, T.J., Rams, W. and Schindler, A. (2001). Customer retention, loyalty, and satisfaction in the German mobile cellular telecommunications market. Telecommunications Policy, 25, 249-269. http://dx.doi.org/10.1016/ S0308-5961(00)00097-5.

Grigoroudis, E. and Siskos, Y. (2010). Customer satisfaction evaluation. London, England: Springer.

Jen, C. and Lien, Y. (2010). What is the source of cultural differences? Examining the influence of thinking style on the attribution process. Acta Psychologica, 133, 154-162. doi:10.1016/j.actpsy.2009.10.011.

Jennings, J. (1996). Global insurance opportunities cited. National Underwriter, 100, p. 23.

Jöreskog, K.G. (1971). Simultaneous factor analysis in several populations. Psychometrika, 36, 409-426. doi: $0.1007 / \mathrm{BF} 02291366$.

Kanungo, R.N. and Jaeger, A.M. (1990). Introduction: The need for indigenous management in developing countries. In: A. Jaeger and R. Kanungo (Eds.), Management in Developing Countries. London: Routledge.

Kottonau, J., Burse, J. and Pahl-Wostl, C. (2000). A consumer memory-based model of new product diffusion within a social network. Computational Social Organizational Science Conference, CASOS, CMU-Pittsburg, PA, July, 21-24.

Lai, F., Griffin, M. and Babin, B.J. (2009). How quality, value, image, and satisfaction create loyalty at a Chinese telecom. Journal of Business Research, 62, 980-986. doi:10.1016/j.jbusres.2008.10.015. 
Liang, B. (2008). Cultural differences in ad information processing: The influence of analytic versus holistic thinking. advances in marketing. Advances in Marketing Proceedings of the Annual Meeting of the Association of Collegiate Marketing Educators. Houston, TX, March 4-8, p. 120.

Markus, H. and Kitayama, S. (1991). Culture and the self: Implications for cognition, emotion, and motivation. Psychology Review, 98, 224-253.

Mittal, V. and Kamakura, W.A. (2001). Satisfaction, repurchase intent, and repurchase behavior: Investigating the moderating effect of customer characteristics. Journal of Marketing Research, 38(1), 131-142. http://www. jstor.org/stable/1558577.

Miyamoto, Y., Nisbett, R.E. and Masuda, T. (2006). Culture and the physical environment: Holistic versus analytic perceptual affordances. Psychological Science, 17, 113-119.

Monga, A.B. and John, D.R. (2004). Consumer response to brand extensions: Does culture matter?. In: B.E. Kahn and M.F. Luce (Eds.), NA-Advances in Consumer Research Volume 31 (pp. 216-222). Valdosta, GA: Association for Consumer Research. http://www.acrwebsite.org/search/view-conferenceproceedings.aspx?Id=8889.

Monga, A.B. and John, D.R. (2007). Cultural differences in brand extension evaluation: The influence of analytic versus holistic thinking. Journal of Consumer Research, 529-536. http://www.jstor.org/stable/10.1086/510227.

Monga, A.B. and John, D.R. (2008). When does negative brand publicity hurt? The moderating influence of analytic versus holistic thinking. Journal of Consumer Psychology, 18, 320-332. doi:10.1016/j.jcps.2008.09.009.

Nguyen, N. and LeBlanc, G. (2001). Image and reputation of higher education institutions in students' retention decisions. International Journal of Educational Management, 15(6), 303-311. doi: 10.1108/ EUM0000000005909.

Nikbin, D., Ismail, I., Marimuthu, M. and Abu-Jarad, I.Y. (2011). The impact of firm reputation on customers' responses to service failure: the role of failure attribution. Business Strategy Series, 12(1), 19-29. doi $10.1108 / 17515631111106849$.

Nisbett, R.E., Peng, K., Choi, I. and Norenzayan, A. (2001). Culture and systems of thought: Holistic versus analytic cognition. Psychological Review, 108(2), 291-310. doi: 10.1037/0033-295X.108.2.291.

Oliver, R.L. (1980). A cognitive model of the antecedents and consequences of satisfaction decision. Journal of Marketing Research, 17(4), 460-469.

Oliver, R.L. (1999). Whence consumer loyalty?. Journal of Marketing, 63, 33-44. http://www.jstor.org/ stable/1252099.

Petty, R.E. and Cacioppo, J.A. (1979). Issue-Involvement Can Increase or Decrease Persuasion by Enhancing Attribute-Relevant Cognitive Responses. Journal of Personality and Social Psychology, 37(10), 1915-26.

Selnes, F. (1993). An examination of the effect of product performance on brand reputation, satisfaction and loyalty. European Journal of Marketing, 27(9), 19-35. doi: 10.1108/03090510043179.

Shamma, H.M. (2012). Toward a comprehensive understanding of corporate reputation: concept, measurement and implications. International Journal of Business and Management; 7(16), 151-169. http://dx.doi.org/10.5539/ ijbm.v7nl6pl51.

Smith, J.D. and Baron, J. (1981), 'Individual Differences in the Classification of Stimuli by Dimensions. Journal of Experimental Psychology: Human Perception and Performance, 7(5), 1132-1145.

Steenkamp, J.B. and Baumgartner, H. (1998). Assessing Measurement Invariance in Cross-National Research. Journal of Consumer Research, 25, 78-90. doi: 10.1086/209528.

Suh, J.-C. and Yi, Y. (2006). When brand attitudes affect the customer satisfaction-loyalty relation: The moderating role of product involvement. Journal of Consumer Psychology, 16(2), 145-155. http://www.sciencedirect. com/science/article/pii/S1057740806700572.

Uskul, A.K., Kitayama, S. and Nisbett, R.E. (2008). Ecocultural basis of cognition: Farmers and fishermen are more holistic than herder. Proceedings of the National Academy of Science of the USA, 105, 8552-8556.

Walsh, G., Evanschitzky, H. and Wunderlich, M. (2008). Identification and analysis of moderator variables Investigating the customer satisfaction-loyalty link. European Journal of Marketing, 42(9/10), 977-1004. doi 10.1108/03090560810891109.

Yang, Z. and Peterson, R.T. (2004). Customer perceived value, satisfaction, and loyalty: The role of switching costs. Psychology \& Marketing, 21(10), 799-822. doi: 10.1002/mar.20030.

Yoon, E., Guffey, H. and Kijewski, V. (1993). The effects of information and company reputation on intentions to buy a business service. Journal of Business Research, 27(3), 215-28. http://dx.doi. org/10.1016/0148-2963(93)90027-M.

Yoon, Y. and Gurhan-Canli, Z. (2004). Cross-Cultural differences in brand extension evaluations: The effect of holistic and analytical processing. Advances in Consumer Research, 31, p. 224.

Zins, A.H. (2001). Relative attitudes and commitment in customer loyalty models: Some experiences in the commercial airline industry. International Journal of Service Industry Management, 12(3), 269-294. doi: 10.1108/EUM0000000005521. 


\section{APPENDIX: SCALE ITEMS}

Repurchase intention (Cronin et al., 2000) 1=very low, $5=$ very high.

1. The probability that I will use this facility's services again is...

2. The likelihood that I would recommend this facility's services to a friend is...

3. If I had to do it over again, I would make the same choice...

Firm reputation (Nguyen and Leblanc, 2001) 1= strongly disagree, 5= strongly agree.

1. In general, I believe that this firm always fulfills the promises that it makes to its customers.

2. This firm has a good reputation.

3. I believe that the reputation of this firm is better than other companies.

Customer satisfaction (Oliver, 1980; Cronin et al., 2000) 1= strongly disagree, $5=$ strongly agree.

1. My choice to purchase this service was a wise one.

2. I think that I did the right thing when I purchased this service.

3. I am totally satisfied with this firm's service.

Holistic-analytic processing (Choi et. al., 2003). 1= strongly disagree, 5= strongly agree.

1. Everything in the universe is somehow related to each other.

2. Even a small change in any element in the universe can lead to substantial alterations in other.

3. Any phenomenon has a numerous number of causes although some of the causes are not known.

4. Any phenomenon has a numerous number of results although some of the causes are not known.

5. Nothing is unrelated.

6. It is not possible to understand the pieces without considering the whole picture.

7. The whole is greater than the sum of its parts.

8. Paying attention to the field is more important than paying attention to its elements. 